\title{
How Do Commercial Children's Foods Influence Their Growth and Development? A Map of Commercially Available Children's Foods in Honduras
}

\author{
Adriana Santana Hernández ${ }^{*}$, Sofía Raquel Mejía Motiño², Adriana Beatriz Di Iorio, \\ Cindy Mérida ${ }^{1}$
}

${ }^{1}$ Food Science and Technology Department, Zamorano University, San Antonio de Oriente, Honduras

${ }^{2}$ Universidad Tecnológica Centroamericana, Tegucigalpa, Honduras

Email: *ahernandez@zamorano.edu

How to cite this paper: Hernández, A.S., Motiño, S.R.M., Di Iorio, A.B. and Mérida, C. (2019) How Do Commercial Children's Foods Influence Their Growth and Development? A Map of Commercially Available Children's Foods in Honduras. Food and Nutrition Sciences, 10, 174-187.

https://doi.org/10.4236/fns.2019.102013

Received: December 7, 2018

Accepted: February 10, 2019

Published: February 13, 2019

Copyright $\odot 2019$ by author(s) and Scientific Research Publishing Inc. This work is licensed under the Creative Commons Attribution International License (CC BY 4.0).

http://creativecommons.org/licenses/by/4.0/

\begin{abstract}
Background: The premature consumption of processed foods with high sugar and sodium content over the course of life has been associated with an increased risk of suffering from chronic diseases starting in adolescence or early adulthood. Methods: There was an examination of the nutritional labelling of processed products for young children $(n=140)$ available in the Honduran market to evaluate their nutritional quality with regard to sodium and sugar content, pursuant to various international recommendations. Results: $54 \%$ of the products evaluated derive more than $20 \%$ of their calories from sugar. The categories that to a large degree exceed the recommended sugar content range are fruit drinks $(80 \%)$ and dessert purees $(65 \%)$. The average price per product serving is lower than one US dollar $(\$ 0.81) .46 \%$ and $6 \%$ of the products place sugar and salt, respectively, among the first five positions in their ingredient lists. Conclusions: Processed foods for infants and young children generally exceed the recommended sugar content, but due to their low cost and easy access, they are displacing traditional food consumption, contributing to increasing childhood obesity and chronic disease in the early stages of life.
\end{abstract}

\section{Keywords}

Fast Foods, Sugar, Infant, Children, Sodium

\section{Introduction}

Complementary feeding includes the transition period in which an infant (a lac- 
tating child up to one year old) transits from exclusive breastfeeding (EBF) to share the family diet [1], and its initiation is recommended starting at six months, according to the World Health Organization (WHO) [2]. It is at this time that alimentary preferences begin to develop and will depend, among other factors, on the types of food that are offered; it is necessary to promote the adequate growth of the child and prevent the adoption of unhealthy eating habits [2], which will have immediate and long-term negative consequences on their growth and development [3].

The first two years of life represent the period of greatest importance to establish the foundations of healthy eating habits by ensuring the acceptance of foods rich in nutrients like fruits and vegetables [2] [3]. Flavors introduced at this stage will affect consumption, given that preferences developed in childhood persist into adulthood [1], and these will be a determinant factor for health.

As a result of globalization and technological progress, there has been a nutritional transition on an international level characterized by lower dietary fiber consumption and an increase in the intake of salt, fats and simple sugars from processed and ultra-processed food [1] [4] promoted to the population at large with highly aggressive marketing tactics. Some of these products are intended for infants under six months old, and as a result it is unsurprising to see very young children inclined to this type of food [5] [6] with clear consequences for their health; this is in spite of WHO recommendation that EBF continue until six months, when complementary feeding should be introduced [2].

As a result of the failure to comply with these recommendations, on a worldwide level there are four million children under five years old suffering from obesity [2], since new generations are growing up in obesogenic surroundings that promote greater energy consumption, mainly of ultra-processed products [4] [7]. Multiple studies have demonstrated that early childhood exposure to products with high sugar and sodium content is correlated with a preference towards this type of food in adulthood and diminishes the ability to self-regulate ingestion, favoring the development of chronic diseases [1] [2] [5] [8].

Despite this situation, there are no national or international laws to regulate the critical nutritional contents (sugar, sodium, fats) of baby food [5] [8] what exists are general recommendations on nutritional content by some specialized public health entities [5].

In some countries, such as Honduras, nutritional labelling is not obligatory, nor are there regulations or specific recommendations for regulating baby food production and marketing to ensure the welfare of infants and young children.

With respect to sodium content, the Codex Alimentarius recommends that children's products have a limit of $200 \mathrm{mg}$ of sodium per $100 \mathrm{~g}$ of product [9]; however, other organizations suggest different limits, such as the United States Department of Agriculture (USDA) [8], which indicates a maximum of $210 \mathrm{mg}$, the US Food and Drug Administration (FDA) [10], which sets a maximum of $260 \mathrm{mg}$, and the Institute of Medicine (IOM), which sets a limit of $300 \mathrm{mg}$ [1], 
all these per serving of product.

For their part, WHO and UK National Diet and Nutrition Survey recommend a simple sugar content of under $10 \%$ of the calories by serving and under $5 \%$ for additional benefits [8] [11]. In addition, WHO and the American Heart Association (AHA) establish $20 \%$ as maximum of sugar-derived calories per serving in processed and ultra-processed food, in general [1] [8] [11] [12].

In the absence of an international agreement on recommendations for sodium and sugar content and the wide range of baby foods marketed, particularly in Honduras, which is an importer of processed foods, it is important to assess products intended for infants and young children available in the country's main supermarket chains and retail stores. Because such products influence the growth and development of this population group in the medium and long term, the goal is to study the nutritional quality of products that are offered, pursuant to the different international recommendations.

\section{Materials and Methods}

An exploratory descriptive study was conducted based on a review of the nutritional labels of processed and ultra-processed foods (hereinafter referred to only as processed) for children offered in Honduras, identifying products by whether or not they comply with the limits for sodium and sugar content established by the different international agencies.

The study was conducted at the Zamorano University (EAPZ) Human Nutrition Laboratory. A number of supermarket chains were selected in the two main cities of Honduras (Tegucigalpa and San Pedro Sula), all with national presence and covering different socio-economic sectors of the market. Similarly, retail outlets open to the public were included order to have both levels of marketing. Repeated products were not included.

The visits were made by personnel appropriately trained in information harvesting in two stages: from June to October 2017 and from July to September 2018. The only inclusion criteria for the study was to take into account all the available foodstuffs on store shelves for lactating babies and small children, without distinction, with labels recommending that they be administered to small children. The product container and nutritional labels were photographed to capture the main nutritional content data, manufacturing data, ingredient list and price. The number of ingredients was identified according to the corresponding list, considering vitamins (any) as one ingredient and minerals (any) as another ingredient. Infant formulas and foodstuffs aimed at children older than 36 months were excluded. There was no internet search for products, because it was preferred to find them at the different points of sale to ensure their availability in the Honduran market; this is the first such study in this area.

\subsection{Sodium Content}

The Codex parameters specific to the category of cereal-based baby food (100 
$\mathrm{mg} / 100 \mathrm{kcal}$ ) [13] were used to identify high sodium products, while the parameters applied to the remaining categories were: the Codex General parameters ( $>200 \mathrm{mg} / 100 \mathrm{~g}$ ) per $100 \mathrm{~g}$ of product, [9] USDA (>210 mg), [8] FDA (>260 mg) [10] and IOM (>300 mg) [1] [12] per serving for products aimed at lactating infants and young children. Products with less than $140 \mathrm{mg} /$ serving were classified as acceptable, those with less than $35 \mathrm{mg} / \mathrm{serving}$ as low sodium, and those with less than $5 \mathrm{mg} /$ serving as without sodium, according to the FDA. [10] In addition, there was a review of the sodium content based on the Pan-American Health Organization (PAHO) nutrient profile, [14] which, although it is not specific to baby food, gives an idea of the ratio between sodium and caloric contribution (rated as excess sodium when it makes up $1 \mathrm{mg} / \mathrm{kcal}$ or more of the product).

\subsection{Sugar Content}

The Codex parameters (7.5 g/100kcal) [13] were used to identify high-sugar content children's products in the category of cereal-based foods, while with the remaining categories, the WHO and UK National Diet and Nutrition Survey [8] recommendations were used to identify products with acceptable sugar content $(<10 \%)$ and those that provide additional benefits $(<5 \%)$ [11]. Following the recommendation of WHO and AHA, the products classified as high in sugar were those whose caloric content derived from sugar per product serving exceeded 20\% [1] [13].

Likewise, there was an evaluation of the presence of salt and sugar (or another type of sweetener) in the ingredient list, with an emphasis on products where these are among the top five positions. The sodium and sugar content in baby foods was evaluated per serving. Based on this information, an Excel 2016 (Microsoft, Redmond, WA, USA) database was prepared with the product name, target age range, manufacturer, manufacturer's country, price, ingredients, serving ( $\mathrm{g}$ ), sodium ( $\mathrm{mg}$ ), sugar ( $\mathrm{g}$ ) and energy (kcal), to make a comparison using the aforementioned criteria and estimate the caloric density, 1:1 ratio of sodium: kilocalories and price/serving. Descriptive measures, specifically frequency distribution tables were used for the data analysis. The baby foods were organized into five categories (Table 1) like those used in the Elliot C. study, [8] composed of 1) snacks, which includes yogurts, cookies/biscuits, corn snacks and fruit snacks, 2) dinner purees, 3) dessert purees and 4) fruit drinks; additionally, a "cereal based" food category was added because the Codex gives specific guidelines for the content of nutrients in this category of product.

\section{Results}

A total of 140 products were evaluated. $70 \%$ of the products were purchased from Tegucigalpa and the surrounding area $(\mathrm{n}=98)$. Once the products were listed, to avoid repetition the remaining $30 \%$ were acquired at points of sale in San Pedro Sula $(n=42)$. The products came from seven countries, mostly from 
Table 1. Categories of baby food and average sodium content (mg) and sugar (\%) per product serving.

\begin{tabular}{ccc}
\hline Product category & $\begin{array}{c}\text { Average sodium } \\
(\mathrm{mg} / \text { serving })\end{array}$ & $\begin{array}{c}\text { Calories derived from sugar per } \\
\text { serving (average percentage) }\end{array}$ \\
\hline Fruit drinks $(\mathrm{n}=10)$ & 12.6 & 87 \\
Dessert purees $(\mathrm{n}=54)$ & 11.1 & 75 \\
Snacks $(\mathrm{n}=29)$ & 24.7 & 33 \\
Yogurt $(\mathrm{n}=10)$ & 36.0 & 53 \\
Fruit snacks $(\mathrm{n}=2)$ & 6.0 & 34 \\
Cookies Biscuits $(\mathrm{n}=11)$ & 9.5 & 21 \\
Corn Snacks $(\mathrm{n}=6)$ & 40.0 & 0 \\
Dinner purees $(\mathrm{n}=17)$ & 33.5 & 28 \\
Cereal based foods $(\mathrm{n}=30)$ & 28.4 & 21 \\
Total sample $(\mathrm{n}=140)$ & 20.7 & 45 \\
\hline
\end{tabular}

the United States (58\%), followed by Mexico (19\%). 12\% of them were from South American countries and the remaining 10\% from Central American countries; $1 \%$ was of European origin. There were no products manufactured in Honduras.

A total of 18 companies were identified that market their products in the country. The largest number of products were manufactured by Gerber Product Company (39\%) of US origin, followed by Nestle of Mexico (16\%) which produces the brands Gerber and Nestum. $11 \%$ of the evaluated products are produced by Beech Nut Nutrition Company also of US origin, whereas $34 \%$ of remaining products were made by 15 companies, among them Irex from Costa Rica, Nutrimental from Brazil and Gourmet from Guatemala.

The majority of products and all the categories represented, were aimed at the consumption of infants from 6 months of age (73\%), followed by products aimed at children older than 12 months (12\%) in the categories mostly of snacks and dessert purees, followed by cereal-based foods. Some products (6\%) were identified as promoted for consumption at 4 months (Beech Nut from Chile and Gerber from the US), specifically in cereal-based food categories, dinner purees and snacks.

In 140 products grouped in the five mentioned categories, that of dinner purée had the highest average sodium content $(33.5 \mathrm{mg}$ ) per serving, followed by cereal-based foods $(28.4 \mathrm{mg})$, while all the categories had elevated sugar-derived calorie content per serving. Fruit drinks presented the highest average sugar-derived calorie content (87\%), followed by dessert purees (75\%), as can be seen in Table 1.

The category of snacks presented high values for the content of one or both of the nutrients. In this same category, corn snacks had the highest sodium content in the whole sample $(40 \mathrm{mg})$ and yogurts had high sugar-derived calorie content $(53 \%)$ and sodium $(36 \mathrm{mg})$ levels above the respective average. 
The average number of ingredients in products in the different categories and subcategories varied from three (fruit snacks) to 14 (cookies/biscuits), followed by corn snacks (12) and yogurt (12), according to the corresponding listing. Thus, the category of snacks had a higher average number of ingredients (10) than the rest: (4) fruit drinks, (7) desert purée, (6) dinner purée and (7) cereal-based foods.

\subsection{Sodium Content}

With the exception of cereal-based foods, none of the products evaluated exceeds the limits established by Codex, USDA, FDA and IOM, since the maximum amount of sodium found was $146 \mathrm{mg}$. According to FDA criteria, $97 \%$ of the products were evaluated as acceptable, low in sodium or without sodium. The remaining $3 \%$ of evaluated food did not indicate its sodium content, representing four products in the dessert puree category, manufactured by the Heinz Company from Mexico.

Additionally, according to the specific criteria established by the Codex to regulate sodium content of cereal-based foods, $3 \%$ of products in this category, specifically the Nestum and Nutribom brands exceeded the recommendation of $>100 \mathrm{mg} / 100 \mathrm{kcal}$ per serving.

Six percentage of total products in the sample, list sodium among the first five positions in the ingredient list. This was mainly observed in the snacks category (47\%), with $100 \%$ of corn snacks and $30 \%$ of yogurts presenting this characteristic.

A review of sodium content per calorie contribution identified that $17 \%$ of the products in the categories of dinner purée and $2 \%$ of dessert purees, exceeded sodium content of PAHO recommendations as well as $67 \%$ of corn snacks, the majority of which had a $1 \mathrm{mg}$ sodium: $1 \mathrm{kcal}$ ratio or excess sodium.

Of the 10 products with highest sodium content (Table 2), four involved the

Table 2. List of the 10 children's foods with the highest sodium content per serving.

\begin{tabular}{lcc}
\hline Manufacturing Company & Product & $\begin{array}{c}\text { Sodium } \\
\text { (mg/serving) }\end{array}$ \\
\hline Nestle Mexico & Gerber Mixed Fruits & 90 \\
Gerber Product Co. Fremont & Autumn Vegetable and Turkey Dinner & 80 \\
Gerber Product Co. Fremont & Garden Vegetable \& Beef Dinner & 70 \\
Nestle Mexico & Carrot Gerber & 65 \\
Gerber Product Co. Fremont & Gerber Vanilla Custard Pudding & 60 \\
Gerber Product Co. Fremont & Banana Yogurt and Fruit Juice Blend & 55 \\
Gerber Product Co. Fremont & Yogurt Blends Strawberry Banana & 55 \\
Gerber Product Co. Fremont & Yogurt Blends Mixed Strawberries & 55 \\
Gerber Product Co. Fremont & Yogurt Blends Strawberry & 50 \\
Gerber Product Co. Fremont & Lil'Crunchies Organic White Bean Hummus & 50 \\
\hline
\end{tabular}


yogurt subcategory and the rest were in dinner purees, dessert purees and one corn snack. All of the products are designed for infants from 6 months of age.

\subsection{Sugar Content}

According to the criteria of the $\mathrm{WHO}$ and AHA, 54\% of the evaluated products are high in sugar, with more than $20 \%$ of their calories derived from it; $7 \%$ complied with the recommendations of WHO and the UK National Diet Survey with less than $10 \%$ of calories from sugar; $3 \%$ complied with $\mathrm{WHO}$ recommendation about the additional benefits of products with less than $5 \%$ of calories from sugar. $22 \%$ of the products in the sample do not refer to the added sugar content among total carbohydrates.

In cereal-based foods and according to the CODEX, $10 \%$ of this type of food exceeds the established content for sugars, whereas $60 \%$ complied with the recommendation. $30 \%$ of the remaining products did not report the amount of sugars in total carbohydrates.

However, $46 \%$ of total products mentioned sugar or brown sugar among the first five positions in the ingredient list. The snacks category showed the largest number of products with this characteristic (52\%), mainly the cookies/biscuits subcategory ( $82 \%$ ), followed by the cereal-based food category (50\%) (Table 3).

Although the fruit drink category has the highest percentage of sugar-derived calories, they are not mentioned in the ingredient lists because there is no breakdown of the ingredients in the fruit concentrate referred to in the list. However, the amount of sugar is indicated in their nutritional labeling per serving. It is for that reason that Table 3 differs from the following one (Table 4) since the products with greater sugar-derived calorie content belong to the categories of fruit drinks (4) and dessert purees (6).

The energy density (ED) of products ready for consumption, by category and according to the recommended age, varies from $0.96 \mathrm{kcal} / \mathrm{g}$ for babies of 4 months of age, to $1.27 \mathrm{kcal} / \mathrm{g}$ for 6 to 12 months and $2.12 \mathrm{kcal} / \mathrm{g}$ for over 12 months of age. By category, as can be seen in Table 5, the highest energy contribution is in corn snacks, whose caloric value comes from sunflower oil, referred to among the first three ingredients in its corresponding listing.

Table 3. Percentage of baby foods by category, whose list of ingredients refers to sugar among the first five positions in their ingredients list.

\begin{tabular}{ccc}
\hline Product category & Number of products & Percentage \\
\hline Snacks & 15 & 52 \\
Coockies/ Biscuits & 9 & 82 \\
Yogurt & 6 & 60 \\
Cereal based foods & 15 & 50 \\
Dessert purees & 20 & 37 \\
Total & 65 & 46 \\
\hline
\end{tabular}


Table 4. List of 10 products with the highest sugar-derived calorie content (percentage) per serving.

\begin{tabular}{ccc}
\hline Manufacturing Company & Product & $\begin{array}{c}\text { Percentage of calories } \\
\text { derived from } \\
\text { sugar/serving }\end{array}$ \\
\hline Carozzi & Vivo Mi Frut: Apple & 96 \\
Good 2 Grow & Good 2 Grow: Fruit punch & 95 \\
Nestle Mexico & Gerber Junior: Pear & 93 \\
Carozzi & Vivo Mi Frut: Pear & 93 \\
Nestle Mexico & Gerber Junior: Apple & 90 \\
Good 2 Grow & Good 2 Grow: Apple & 90 \\
Gerber & Gerber: White Grape Juice & 89 \\
Materne North Corp. & Gogo Squeez: Applecinnamon & 88 \\
Nestle Mexico & Gerber Junior: Peach & 87 \\
Gerber Product Company & Gerber: Organic Apple Juice & 87 \\
Average percentage of calories derived from sugar & 91 \\
\hline
\end{tabular}

Table 5. Energy density average per product category.

\begin{tabular}{cc}
\hline Product category & Average energy density $(\mathrm{kcal} / \mathrm{g})$ \\
\hline Snacks $(\mathrm{n}=29)$ & 3.33 \\
Corn snacks $(\mathrm{n}=6)$ & 4.39 \\
Cookies/ Biscuits $(\mathrm{n}=11)$ & 3.68 \\
Yogurt $(\mathrm{n}=10)$ & 2.29 \\
Fruit snacks $(\mathrm{n}=2)$ & 1.89 \\
Dessert Purees $(\mathrm{n}=54)$ & 0.69 \\
Dinner purees $(\mathrm{n}=17)$ & 0.64 \\
Fruit drinks $(\mathrm{n}=10)$ & 0.55
\end{tabular}

\subsection{Price per Serving}

Foods by full container, from lowest to highest price, were the dessert purees $(\$ 0.92)$, dinner purees $(\$ 1.84)$ and cereal-based foods $(\$ 3.61)$. The cost per serving (Table 6), calculated according to the number of servings in the container is lowest in the category of cereal-based food products $(\$ 0.25)$, dessert purées (\$0.79); cookies/biscuits (\$0.62), and corn snacks (\$0.77), the last two in the category of snacks (\$1.13).

\section{Discussion}

Despite the numerous benefits of EBF, the number of infants who eat any type of food before 6 months of age continues to increase. Concerns and misinformation of parents and contradictory messages from advertising media and unethical health professionals contribute to the decline in the percentages of EBF [2]. U.S. Companies like Beech Nut and Gerber recommend 4 months as a minimum 
Table 6. List of the average price by baby food category per product serving.

\begin{tabular}{cc}
\hline Product category & Average price in dollars ${ }^{\mathrm{a}}$ per serving \\
\hline Fruit drinks $(\mathrm{n}=10)$ & $\$ 1.44$ \\
Dinner purees $(\mathrm{n}=17)$ & $\$ 1.17$ \\
Snacks $(\mathrm{n}=29)$ & $\$ 1.13$ \\
Fruit snacks $(\mathrm{n}=2)$ & $\$ 1.60$ \\
Yogurt $(\mathrm{n}=10)$ & $\$ 1.48$ \\
Corn snacks $(\mathrm{n}=6)$ & $\$ 0.77$ \\
Cookies/ Biscuits $(\mathrm{n}=11)$ & $\$ 0.62$ \\
Dessert Purees $(\mathrm{n}=54)$ & $\$ 0.79$ \\
Cereal based foods $(\mathrm{n}=30)$ & $\$ 0.25$ \\
Average price of children's food products & $\$ 0.81$ \\
\hline
\end{tabular}

${ }^{\mathrm{a} E x c h a n g e ~ r a t e ~ t o ~ L . ~} 24.10$ (Central Bank of Honduras) [15].

age for consumption of their products, when food intake at this age should be the exception and not the norm [5]. Breastfeeding must be protected and promoted to generate a collective conscience regarding its benefits and advantages [2] [16] in order to prioritize the health and nutrition of the lactating babies and small children to the maximum since at a world-wide level the health risks of acquiring harmful nutritional habits is greatest for three of every five lactating babies of six months and up that did not receive EBF [17].

The market for this type of products is very broad, with a wide range of processed products aimed at infants and young children [8] [9] [18], which, added to the lack of regulation in the nutritional content of the same, seems to be an open and inexhaustible market for the food industry, according to the findings of this and other studies carried out in different latitudes [1] [2] [8]. Globalization, urbanization and increased family income have generated an increase in the production, sale and consumption of this type of food [3].

During the 2000-2013 period, sales in Latin America increased by $50 \%$ due to the adoption of economic and market policies by the Latin American countries, which promote the international flow of goods and the deregulation of markets [19] [20] such as the Free Trade Agreements (FTAs) that establish norms to facilitate trade between countries through the free exchange of food or services with the aim of generating greater economic and social growth. One of these treaties between Honduras and the United States is CAFTA-DR (Central America Free Trade Agreement, Dominican Republic) [20] [21], which is evidenced by the fact that almost half of commercial foods in the sample of products evaluated for infants and young children, come from the United States, without finding any of Honduran origin.

In this way, the consumer is exposed to an offer of products that compete with traditional foods prepared in a homemade style, leading to a loss of family traditions. Likewise, these trade policies favor large food industries such as transnational companies, with extremely high sales that grant them certain political 
power and the capacity to influence national policies, affecting the supply of healthy foods and the consumption of food products [19] [20]. Therefore, policies are essential for the regulation of the baby food market in order to ensure infants' well-being.

According to the results, these products are an obstacle to adequate nutrition because of their high sugar content. In yogurt, which is usually considered a healthy food due to its probiotic properties [22], more than half of products in this category presented an excess of sugar content. Many of the processed products, generally those of lower nutritional quality are available at lower prices ( $\$ 0.81$ on average), making them physically and economically accessible, as well as attractive for their advertising and for being of recognized brands; these factors greatly influence the consumer's decision [23].

\subsection{Sodium Content}

More than $70 \%$ of daily sodium intake in adults comes from processed and packaged foods [8] [10] [24]. In Latin America, a study in Argentina showed that $27 \%$ of commercial foods for children had excess sodium [23]. Given that both infants and young children are similarly consuming processed foods, studies reveal that almost $80 \%$ of them consume more than $1900 \mathrm{mg}$ of sodium per day, exceeding WHO recommendations ( $1 \mathrm{~g}$ for lactating infants 6 - 12 months old and $2 \mathrm{~g}$ for children with ages between 1 - 3), and IOM recommendations (1500 mg for children 1 - 3 years old) [1] [8] [24] [25]. IOM reports reveal that $79 \%$ of children aged between 1 - 3 exceed the daily recommendation for sodium intake [25].

Multiple studies have reported that the excessive sodium content in commercial foods aimed at infants and young children stimulates appetite, leading to a greater consumption and preference for this type of products [1] [8] [12] [23] [25] [26], which is reflected in the increase in blood pressure values, mainly in obese children, raising the risk of developing cardiovascular diseases [12] [24] [25].

Results of the Elliot study [8] (2010), show that $12 \%$ of infant foods in Canada exceed the recommended sodium content, while another study conducted in New York [12] indicates that $15 \%$ of products available in the city contain high sodium content. In the present study, according to the recommendations of CODEX, USDA and FDA, none of the evaluated products (without considering the cereal-based foods), exceeded the acceptable sodium content, which coincides with the decrease in the percentage of products with excess sodium and an increase in the number of products with excess sugar in the global market [27].

However, the categories that exceed their content with a ratio of $1 \mathrm{mg}$ of sodium: 1 kilocalorie, and that refer to this in the list of ingredients, include corn snacks. Due to lack of knowledge of the parents or caregivers, probably guided by the brand and advertising, they provide this type of product to infants and young children, considering that they are safe for their health. The younger that 
these products are facilitated, the greater the problems that may arise, not only related to hypertension, but also to proper kidney functioning, reinforcing the need for cohesive measures to reduce levels of both sodium and sugar in food products aimed at infants and young children that intend to manipulate their palate, stimulate appetite and generate addiction to these foods [1] [24].

\subsection{Sugar Content}

The premature introduction of sugars, influences self-regulation of intake and increases the risk of developing chronic diseases such as type 2 diabetes and dental caries, directly affecting the national healthcare budgets [1] [28]. Sugars should be consumed naturally in foods that, in addition, provide other essential nutrients [29]. Experts advise prolonging their introduction as long as possible and even recommend that natural fruit juices be consumed after 12 months of age [3] [30].

Studies carried out by Elliot $(2010,2015)$ [8] [12], identified that more than half of the evaluated products aimed at infants (53\% and 56\%, respectively), exceeded $20 \%$ of the calories derived from sugar, while the one conducted in 2014 by Samuel et al., in Canada [1], identified $60 \%$ under the same conditions. Similar findings were identified in the current study (54\%), which suggests that the situation in terms of sugar content has not improved in the offer of processed foods for this population group. The fact that Honduras is an importer of food mainly from the United States has resulted in an increasing trend in the supply of this type of products with higher than recommended sugar levels to the region.

Sugary drinks are not recommended nor necessary during the complementary feeding period; they are the main source of added calories and sugar in the diet [31]. However, the results of the Feeding Infants and Toddlers study show that the consumption of these foods begins prematurely in infancy [3] [30], while similar studies show an increase in the body mass index two years after the first consumption [32]. In the results of the present study, the category of fruit drinks has the highest sugar content, since, on average, approximately $90 \%$ of their calories are derived from sugar and more than $80 \%$ exceed the recommended amount. This coincides with the findings reported by Elliot [12] and Samuel et al. [1], which determined that the content of added sugars in the categories of dessert purees and snacks (mainly in yogurt), were equally alarming.

The two mentioned studies also show the relationship between the price and nutritional quality with the most sugary products having the lowest cost, which contributes to the obesogenic effect [1]. It is noteworthy that in the lower-income sectors, processed products that target a population that is older than the infant population are often provided to infants and young children; these products contain similar or higher levels of sugar, because they are available at even lower costs [19] [30] [33].

Sodium and sugar share several functions as food ingredients and are used as 
flavor enhancers. Sugar can enhance natural flavors, such as meats and vegetables, without these having a sweet taste, therefore, categories such as dinner purees show a high sugar content (28\%) despite not having a sweet taste [27].

With regard to energy density, it increases according to the age of the population to which the product is recommended, and it should be noted that snacks as a whole are the ones with the highest energy density, as well as sodium content, particularly corn snacks, which in addition, induce young children to an addiction to this type of products, resulting in the detriment of their health.

\section{Conclusions}

In Honduras, there is a wide range of imported processed foods for infants and young children that, in spite of the false notion of being nutritionally adequate or even beneficial, mostly exceed the recommendations of at least one critical nutrient, which generates short and long-term negative impacts in the health of consumers.

Although the present study took a sample of products in the two main cities of Honduras, it gives an idea of the general panorama on the content of sodium and sugar in commercialized baby foods, the lack of regulation and the wide indiscriminate offer, with insufficient information for parents or caregivers to make the best choice of products, to the detriment of the health of infants and young children.

Approximately half of the products evaluated included sugar in the first five positions of the list of ingredients; this is similar to the results reported in previous studies. With regard to sodium content, less than $10 \%$ of products referred to it as an ingredient in the first five positions of the corresponding list, although in both cases, their content is not necessarily mentioned in the list of ingredients, which makes it difficult for caregivers to select this type of product.

A low product cost was identified in products with higher sugar content; these were followed by snacks, which were identified as the products with the highest sodium content, greater number of ingredients, energy density and low cost per serving. Both of the above mentioned products have been established as highrisk foods to children's health.

It is necessary to develop national policies that require a clear and mandatory nutritional labeling in packaged products; this should include a respective description and warnings about the content of critical nutrients. Likewise, it is important to have a universal nutritional profile for this age group prepared by scientific institutions that does not show conflicts of interest.

Finally, collective educational campaigns are required to guide parents and caregivers in order to teach them to discern which the best foods for their children are during this critical stage and thus make informed purchasing decisions, selecting foods according to their nutritional quality.

\section{Acknowledgements}

The authors thank the Institute for Technology in Health Care (ITHC), which 
agreed to finance the acquisition of children's meals to carry out the study.

\section{Conflicts of Interest}

The authors declare no conflicts of interest regarding the publication of this paper.

\section{References}

[1] Samuel, L., Ethan, D., Basch, C. and Samuel, B. (2014) A Comparative Study of the Sodium Content and Calories from Sugar in Toddler Foods Sold in Low- and High-Income New York City Supermarkets. Global Journal of Health Science, 6, 22-29. https://doi.org/10.5539/gjhs.v6n5p22

[2] Miles, G. and Siega-Riz, A. (2017) Trends in Food and Beverage Consumption among Infants and Toddlers: 2005-2012. Pediatrics, 139.

https://doi.org/10.1542/peds.2016-3290

[3] Álvarez, M., Serna, S., Villada, M. and López, B. (2012) Instant Rice Porridge for Children Aged 12 to 36 Months Fortified with Micronutrients: An Alternative for Infant Feeding. (Papilla de arroz instantánea para niños de 12 a 36 meses fortificada con micronutrientes: Una alternativa para la alimentación infantil.) Journal of Engineering and Technology, 1.

[4] Pajuelo-Ramírez, J. (2017) Obesity in Peru. (La obesidad en el Perú). An. Fac. Med., 78, 179-185

[5] Basulto, J., Ojuelos, F., Baladia, E. and Manera, M. (2016) Sugars in Children's Foods. The Spanish and European Regulations, Who Does It Protect? (Azucares en alimentos infantiles. La normativa española y europea, ¿a quién protege?) Revista Pediatría de Atención Primaria, 18, 1139-7632.

[6] Specht, I., Rohde, J., Olsen, N. and Heitmann, B. (2018) Duration of Exclusive Breastfeeding May Be Related to Eating Behavior and Dietary Intake in Obesity Prone Normal Weight Young Children. Plos One, 13. https://doi.org/10.1371/journal.pone.0200388

[7] National Institute of Public Health of Mexico (2016) Analysis of Regulations and Practices for the Labeling of Food and Drinks for Children and Adolescents in Some Latin American Countries (Argentina, Chile, Costa Rica and Mexico) and Recommendations to Facilitate Consumer Information.

[8] Elliott, C. (2010) Sweet and Salty: Nutritional Content and Analysis of Baby and Toddler Foods. Journal of Public Health, 33, 63-70. https://doi.org/10.1093/pubmed/fdq037

[9] Codex Alimentarius (1981) Standard for Packaged Foods for Infants and Children Codex Stan 73-1981.

[10] US Food and Drug Administration (2018) Sodium in Your Diet.

[11] World Health Organization (2014) WHO Opens Public Consultation on Draft Sugars Guideline.

[12] Elliott, C. and Conlon, M. (2015) Packaged Baby and Toddler Foods: Questions of Sugar and Sodium. Pediatric Obesity, 10, 149-155. https://doi.org/10.1111/j.2047-6310.2014.223.x

[13] Codex Alimentarius Commission (2000) Request for Comments and Information on the Revised Draft Standards for Processed Cereal-Based Foods for Infants and Young Children. 
[14] Panamerican Health Organization (2016) Nutrient Profile Model of PAHO.

[15] Central Bank of Honduras BCH (2018) Dollar Exchange Rate.

[16] Food and Agriculture Organization FAO (1976) Declaration on Infant Feeding.

[17] United Nations Children's Fund UNICEF (2016) From the First Hour of Life: Making the Case for Improved Infant and Young Child Feeding Everywhere.

[18] Food and Agriculture Organization FAO (1991) Guidelines on Complementary Food Preparations for Older Infants and Young Children.

[19] Panamerican Health Organization (2015) Ultra Processed Foods and Beverages in Latin America: Trends, Effect on Obesity and Implications for Public Policies.

[20] Bejarano-Roncancio, J., Gamboa-Delgado, E., Aya-Baquero, E. and Parra, D. (2015) The Ultra-Processed Foods and Beverages That Enter Colombia through the Free Trade Agreement Will Influence the Weight of Colombians? Revista Chilena de Nutricion, 42, 409-413. https://doi.org/10.4067/S0717-75182015000400014

[21] Foreign Trade Information System SICE (2018) Information about Honduras.

[22] Li, P., Tian, W., Jiang, Z., Liang, Z., Wu, X. and Du, B. (2018) Genomic Characterization and Probiotic Potency of Bacillus sp. DU-106, a Highly Effective Producer of L-Lactic Acid Isolated from Fermented Yogurt. Frontiers in Microbiology, 9, 2216.

[23] Piaggio, L. and Solans, A. (2017) Ultra-Processed Fun: Food Products Aimed at Boys and Girls in Supermarkets in Argentina. Approach to Advertising Strategies and Nutritional Composition. Diaeta, 35, 9-16.

[24] Saieh, C., Lara, M., Opazo, M. and Castro, M. (2015) Sodium and Potassium Intake in Children 0 to 15 Years Old: Observed versus Expected. Revista Médica Clínica Las Condes, 26, 537-543.

[25] Cogswell, M., Gunn, J., Yuan, K., Park, S. and Merritt, R. (2015) Sodium and Sugar in Complementary Infant and Toddler Foods Sold in the United States. Pediatrics, 135, 416-423. https://doi.org/10.1542/peds.2014-3251

[26] Maalouf, J., Cogswell, M., Gunn, J. and Merritt, R. (2018) Sodium Content of Commercial Baby and Toddler Foods. Pediatrics, 127.

[27] Golfein, K. and Slavin, J. (2015) Why Sugar Is Added to Food: Food Science 101. Comprehensive Reviews in Food Science and Food Safety, 14, 644-656.

https://doi.org/10.1111/1541-4337.12151

[28] World Health Organization (2015) Sugar Intake for Adults and Children.

[29] Gil-Campos, M., San José, M.A. and Díaz, J.J. (2015) Use of Sugars and Sweeteners in the Child's Diet. Recommendations of the Nutrition Committee of the Spanish Pediatric Association. Annals of Pediatrics, 83, 295-364.

[30] Chaidez, V., McNiven, S., Vosti, S. and Kaiser, L. (2014) Sweetened Food Purchases and Indulgent Feeding Are Associated with Increased Toddler Anthropometry. Journal of Nutrition Education and Behavior, 46, 293-298. https://doi.org/10.1016/j.jneb.2013.05.011

[31] Martínez, A. (2016) Sugars in the Diet of Children: The Enemy at Home. Revista Pediatría de Atención Primaria, 18, 11-13.

[32] Farro, K., Montero, I., Vergara, E. and Ríos-Castillo, I. (2018) High Consumption of Sugars and Fats in Pre-School Children of Panama: Cross-Sectional Study. Revista Chilena de Nutrición, 45, 7-16.

[33] Hernández, A., Di Iorio, A., Lansdale, J. and Salazar, M. (2018) Characterization of the Types of Sweeteners Consumed in Honduras. Nutrients, 10, E338. 